\title{
Relationship between occupational stress, emotional intelligence, and self-efficacy among faculty members in faculty of nursing Zagazig University, Egypt
}

\author{
Sahar Hamdy El-Sayed ${ }^{1}$, Hanaa Hamdy Ali EI -Zeiny² , D.A. ADEYEMO³ \\ 1. Nursing Administration Department, Faculty of Nursing, Zagazig University, Egypt. 2. Psychiatric and Mental Health \\ Nursing Department, Faculty of Nursing, Zagazig University, Egypt. 3. Guidance and Counseling Department, Faculty of \\ Education, University of I badan, I badan, Nigeria.
}

Correspondence: Sahar Hamdy El-Sayed. Address: Nursing Administration Department, Faculty of Nursing, Zagazig University, Ash Sharqiyah, Egypt. Email: saher_hamdy2006@yahoo.com

Received: November 1, $2013 \quad$ Accepted: February 13, $2014 \quad$ Online Published: March 11, 2014

DOI : 10.5430/jnep.v4n4p183 URL: http://dx.doi.org/10.5430/jnep.v4n4p183

\begin{abstract}
Background/Aim: Different studies, in international context, have linked occupational stress to emotional intelligence or self-efficacy of faculty members. However, investigating the relationship between these three constructs in this context was limited. So, the researchers investigated the relationship between occupational stress, emotional intelligence and self-efficacy among faculty members.
\end{abstract}

Method: The study was conducted at the Faculty of Nursing, Zagazig University using a descriptive correlational design. A convenience sample of 91 faculty members working in Faculty of Nursing Zagazig University during the academic year 2011-2012 were recruited for the study. Four tools were used for data collection: Questionnaire about demographic data, Emotional Intelligence Scale, General Self-Efficacy Scale, and Occupational Stress Scale.

Results: The study findings indicate that the majority of faculty members experience a high level of occupational stress, while they have a low level of emotional intelligence and self-efficacy. The occupational stress was negatively related with faculty members' emotional intelligence and self-efficacy.

Conclusion and Recommendation: The findings of current study confirm that occupational stress has negative relationships with the faculty members' emotional intelligence and self-efficacy. Therefore, we suggest that the Faculty of Nursing should keep the stress level of their faculty members lower and help them to stay healthier by holding training courses on emotional intelligence improving their social skills and increase their efficiency at work. Moreover, the perceived self-efficacy can be improved among the faculty members through training programmes and courses this would help the faculty members enhance their stress bearing capacity and also improve their productivity.

\section{Key words}

Faculty members, Occupational stress, Teacher's self-efficacy, Emotional intelligence

\section{I ntroduction}

Occupational stress has increasingly been recognized as a widespread problem in different educational settings ${ }^{[1]}$. Although the reasons may differ, all of them may experience stress in their job ${ }^{[2]}$. However, even encountering similar 
work stress, some teachers may be less vulnerable to stress than others. Therefore, it seems natural that one should raise the question as to why some teachers could be less vulnerable to stress than others in the face of similar work stress. In this connection, an examination of personal and organization factors that enable teacher to deal with job stress seems advisable ${ }^{[1]}$. One personal coping resource that is the concern of the present study is self-efficacy. Bandura stated that people with high efficacy beliefs persisted with the task in the face of difficulty and achieved higher results with lower levels of stress ${ }^{[3]}$. The second is emotional intelligence: An emotionally intelligent teacher learns and applies emotional intelligence to improve stress management, which would raise the quality of teacher and quality of education ${ }^{[4,5]}$.

The study aims to investigate the relationship between occupational stress, emotional intelligence and self-efficacy among faculty members in Faculty of nursing Zagazig University, Egypt. The research question was "Is there a significant relationship between occupational stress, emotional intelligence and self-efficacy of faculty members?"

\section{Background}

Occupational stress is known as stress at work and considered one of the leading causes of work-related health problems in almost all professions around the world ${ }^{[6]}$. It is defined as a combination of high levels of job demands and low levels of control over one's job ${ }^{[7]}$.

University teachers face problems either with the institutional or governmental side, which have negative effects on their effectiveness in teaching and learning process. The institutional problems include; poor management, excessive work hours, rigid institutional policies, heavy workload, poor student behavior, poor relationships with colleagues, poor working conditions that include diminishing resources and poor physical features of school buildings, lack of reward, and role ambiguity. On the other side, the governmental problems include; ever changing higher reforms and policies, less than adequate budget for higher education sector, quality control and accreditation concerns. These constitute potential sources of stress to university teachers ${ }^{[8-11]}$. The preparation of examination results, lack of research facilities, lack of annual leave/ holiday, manuscript preparation, slow progress on career advancement, and frequent interruptions are of them causes of stress among academic staff ${ }^{[12]}$.

Several studies have shown that occupational stress can lead to various negative consequences for the individual and the workplace ${ }^{[13]}$. Stress in the workplace can ultimately rob people of their spirit and passion for the job, resulting in impaired individual functioning, low motivation and decreased morale ${ }^{[14]}$. As well, dampened initiative, reduced interest in working, high absenteeism rates, decreased capacity to perform, poor job performance, reduced efficiency, poor quality control, low quality products and services, and poor health, poor mental and physical wellbeing ${ }^{[15]}$.

The harmful effects of stress are reduced by many factors related to the individual and the organization, two of the most important of these factors are emotional intelligence and self-efficacy that protect from the experience of job strain ${ }^{[16]}$. Emotional intelligence has been defined as the ability of a person to recognize and understand one's own emotions and those of others and regulate or manage those emotions so as to motivate self and others for achieving specific goals ${ }^{[17]}$.

In this respect, Bar - On ${ }^{[18]}$ proposed a new model of emotional intelligence which provides a theoretical basis for the emotional quotient inventory (EQ-I), which was originally designed to assess various aspects of this construct as well as to examine its conceptualization. In this model, emotional-social intelligence is viewed as an integration of interconnected emotional and social competencies, skills and factors that determine how successfully we convey ourselves, realize others and communicate with them, and deal with the daily necessities and problems. This model has one or more of the following components: (a) the ability to recognize, understand, and express emotions and feelings; (b) the ability to understand how others feel and relate with them, (c) the ability to manage and control emotion; (d) the ability to manage change, adapt, and solve problems of a personal and interpersonal nature and the ability to generate positive effects and be self-motivated ${ }^{[18]}$. 
Emotional Intelligence plays an important role to low down the stress level among teachers ${ }^{[19]}$. University teachers with high level of emotional intelligence use mechanisms which help them to adapt to environmental changes. Teachers with low level of emotional intelligence on the other hand lack this ability to adapt properly to changing conditions ${ }^{[20,21]}$.

Self-efficacy is another factor whose contribution to occupational stress was investigated in the present study. Concept of self-efficacy, that is the belief in one's capabilities to organize and execute the courses of action required to produce given attainments ${ }^{[22]}$. In educational field, teacher's self-efficacy refers to the beliefs teachers hold regarding their capability to bring about desired instructional outcomes ${ }^{[4]}$.

Bandura highlighted that individuals' belief regarding their self-efficacy forms the main part of their self-awareness. For creating and changing the self-efficacy belief system, four important sources have been determined. These sources are: mastery experiences, vicarious experiences, social persuasion, and psychological responses to experiences. Mastery experiences are situations in which people perform successfully. Vicarious experiences are situations in which people observe others perform successfully, compare themselves to that performance, and form beliefs about their own competencies. Social persuasion is feedback from others that is judged to be authentic and a reasonable match to one's personal assessment of capabilities. Physiological responses are physical and emotional reactions to situation ${ }^{[22]}$.

Teachers' sense of self-efficacy plays a key role in influencing important academic outcomes. It is related to higher levels of student achievement and motivation, and has been shown to influence teachers' instructional practices, use of innovative teaching methods, enthusiasm, commitment, and teaching behavior ${ }^{[23]}$. Self-efficacy affects the level of mental stress and pressure and the depression caused from threatening situations. Individuals with high self-efficacy, reduce their mental stress during stressful situations. Though, individuals with low self-efficacy experience a high level of stress in controlling threats and they expand their lack of self-efficacy and they see many environmental aspects as dangerous and threatening, which this matter can lead to mental stress for an individual ${ }^{[24,25]}$.

Various studies were carried out in Europe, Asia and America to examine the relation between emotional intelligence and occupational stress among faculty members and secondary school teachers ${ }^{[8,16,26]}$. Other studies investigated the relationship between self-efficacy and occupational stress ${ }^{[1,24,25]}$. However, one study only was carried out or reported on the relationship between these three constructs in Africa (Nigeria) ${ }^{[27]}$, thereby, leaving a gap to fill in Egypt. Thus, what is the relationship between the three variables among nursing faculty members? This study seeks to find answers to the question.

This work is anchored on Salovey and Mayer's Ability Based Model of emotional intelligence explains that the level of emotional intelligence will increase individuals' competencies and this can increase their ability to decrease stress situations and increase positive individual attitudes and behaviors ${ }^{[28,29]}$. As well, the Bandura's Social Cognitive Theory represents a broad framework for the study that asserts a strong negative relationship between perceived self-efficacy and perceived stress. In this way, Bandura's Social Cognitive Theory considers the experience of stress in terms of low efficacy for exercising control over stressful situations or conditions ${ }^{[22]}$.

The work life of faculty members is not easy. This situation arises from diverse factors; the pressure from increased workload, inadequate basic facilities for teaching, learning and research, and not so suitable work environment which can lead to depression, irritability, nightmares and being introverted. So, faculty members in this setting need skills such as emotional intelligence and sense of self efficacy to be able to manage these emotions which may interfere with personal, professional and daily working lives, which create an urgent need for researchers to investigate the relationship between occupational stress, emotional intelligence, and self-efficacy among faculty members. 


\section{Methods}

\subsection{Research design}

The study used a descriptive correlational design.

\subsection{Ethical considerations}

The researchers obtained the official permission to conduct the study from the Dean of the Faculty of Nursing, Zagazig University, Egypt, because there is not an ethical committee. An individual informed consent was obtained from each participant after full explanation of the study objectives and procedures. Participants were reassured that participation is totally voluntary, that the information provided by them will be treated with utmost confidentiality.

\subsection{Setting}

The study was conducted at the Faculty of Nursing, Zagazig University, Egypt. Zagazig University was founded in 1974 as a state university to create and transfer knowledge that will enable to make useful contributions to their communities and provide professional leadership at global level. The Faculty of Nursing consists of six academic departments: Nursing Administration, Community Health Nursing, Pediatric Nursing, Medical Surgical Nursing, Psychiatric and Mental Health Nursing, and Obstetric and Gynecological Nursing. Over 1200 undergraduate students are currently enrolled in the four year nursing program.

\subsection{Sample}

A sample of convenience of 91 faculty members working in the Faculty of Nursing, Zagazig University, Egypt, during the academic year 2011-2012. From which 27 teaching staff (5 assistant professors \& 22 lecturers) and 64 assistants teaching staff (22 assistant lecturers \& 42 demonstrators). There were no exclusion criteria.

\subsection{Instruments}

Four tools were used in this study: Questionnaire about demographic data, Emotional Intelligence Scale (EIS), General Self-efficacy Scale (G.S.E.S) and Occupational Stress Scale (OSS). The questionnaire about demographic data was intended to collect data about the personal characteristics of the participants. These included age, educational qualification, academic rank, department, years of experience in teaching nursing, marital status, and monthly income.

Emotional Intelligence Scale (EIS): was developed by Schutte et al. ${ }^{[30]}$. To assess faculty member's emotional intelligence based on self-report responses to 33 items grouped under five subscales; the appraisal and expression of own and others' emotions (12 items), regulations of emotions in self and others (5 items), social skills ( 5 items), utilization of emotions in solving problems ( 7 items), and optimism ( 4 items). Participants responded by indicating their agreement with each of the 33 statements using a five-point scale ranging from 1 (Strongly disagree) to 5 (Strongly agree). The scores ranged from 33 to 165 . Emotional intelligence was considered to be high if the percent score was $75 \%$ or more and low if less than $75 \%{ }^{[31]}$. The instrument previous reliability was reported by Schutte et al. and Jude ${ }^{[30,32]}$. The Cronbach's alpha of EIS ranged from 0.87 to 0.90 and 0.83 to 0.87 , respectively. The instrument was validated by Akpochafo ${ }^{[33]}$, the content validity of the instrument yielded $79.59 \%$ and the construct validity range between .45 and .96 .

General Self-Efficacy Scale (GSES): was developed by Schwarzer and Jerusalem ${ }^{[34]}$ to assess self-efficacy of faculty members. It consisted of 10 statements (It is easy for me to stick to my aims and accomplish my goals and I can solve most problems if I invest the necessary effort). Responses were evaluates using a four-point Likert scale ranging from 1 (Not at all true) to 4 (Exactly true). The scores ranged from 10 to 40 . Self-efficacy was considered to be high if the percent score was $75 \%$ or more and low if less than $75 \%{ }^{[34]}$. The instrument previous reliability was reported by Salami; Akpochafo; Schwarzer and Jerusalem ${ }^{[15,33,34]}$, the Cronbach's alpha of GSES ranged from 75 to $.90,75$ to $.90 \&$ the $\alpha=0.78$ 
respectively. The instrument was validated by Akpochafo ${ }^{[33]}$, the content validity of the instrument yielded $76.50 \%$ and the construct validity range between .51 and .92 .

Occupational Stress Scale (OSS): was developed by Hassan and Hassan ${ }^{[35]}$ and modified by the researchers to measure a variety of stressful job situations among faculty members. Participants responded by indicating their level of agreeableness to each of the 39 statements grouped under nine subscales; work overload (12 items); administration and management (6 items); interpersonal problems and colleagues (5 items); job promotion (4 items); work scheduling (2 items); inadequate resources ( 1 item); lack of rewards (4 items); job insecurity ( 2 items); and poor working condition (3 items). Participants responded by indicating their agreement with each of the 39 statements using a five-point scale ranging from 1 (Never like me) to 5 (Always like me). The scores ranged from 39 to 195. Occupational stress was considered to be high if the percent score was $75 \%$ or more and low if less than $75 \%{ }^{[6]}$. The instrument previous reliability was reported by Hassan and Hassan ${ }^{[35]}$, the OSS has demonstrated a high internal consistency (Cronbach $\alpha$ ranged from 0.79 to 0.87 ). The reliability estimate of the scale for the present study was $\alpha=0.83$. The validity of the scale was not reported by the previous authors.

\subsection{Procedure}

Before data collection, face and content validity of the tools through rigorous review by a group of experts in nursing administration were ascertained. The group consisted of 9 faculty members, from the Faculty of Nursing at Zagazig and Ain Shams universities. Their comments factored into fine tuning of the instruments. The researchers carried out a pilot study on a sample of 9 faculty members from different departments. The purpose was to ascertain the feasibility of the study and the clarity and applicability of the tools. It also helped to estimate the time needed for filling in the instruments. Based on the results of the pilot, no modifications were needed and data of those participants were incorporated in the main study results.

Before the distribution of the tools to be filled in, the researchers explained the objectives of the study to participants in order to receive the reliable data. Each participant received a copy of the tools. The scales were filled in by the participants, while they were on duty and collected immediately after completion. The participants were allowed to keep the scales with them, filled them in and could submit them within one week. The nature of the participants' job and the number of tools involved in the study accounted for the delay in the collection of the scales. The time required for completion of the tools was found to range from 30-45 minutes. The collection of data lasted two months starting from the beginning of March to the end of April 2012.

\subsection{Data analysis}

Data were analyzed using descriptive statistics in the form of frequencies and percentages for qualitative variables, the qualitative categorical variables were compared using chi-square test. Pearson correlation analysis was used for assessment of the inter-relationships among quantitative variables. Statistical significance was considered at $p<.05$.

\section{Results}

Table 1 displays the characteristics of the participants. All 91 faculty members agreed to participate in the study. The participants were all women, with a mean age of $30.93 \pm 6.26$. Less than half $(46.2 \%)$ had baccalaureate degree in nursing and are demonstrators. Less than quarter (23\%) of participants work in Medical Surgical Nursing department. Less than two thirds (64.8\%) of participants were married and had monthly income 1500 L.E. and more. The average years of experience teaching nursing was $9.53 \pm 5.17$ years.

Table 2 represents components of overall level of emotional intelligence of participants. The highest percentage of the participants (79.1\%) obtained low level of emotional intelligence, while few of them (20.9\%) obtained a high level of 
emotional intelligence. The highest percent is for optimism, (47.3\%), and the lowest percent is for regulations of emotions in self and others (12.1\%).

Table 1. Characteristics of Participants $(\mathrm{No}=91)$

\begin{tabular}{|c|c|c|}
\hline Items & No & $\%$ \\
\hline \multicolumn{3}{|l|}{ Age in years: } \\
\hline$>25$ & 21 & 23.1 \\
\hline $25-$ & 43 & 47.2 \\
\hline $35+$ & 27 & 29.7 \\
\hline \multicolumn{3}{|l|}{ Educational qualification: } \\
\hline Baccalaureate degree in nursing & 42 & 46.2 \\
\hline Baccalaureate degree in nursing $+\mathrm{MSC}$ & 22 & 24.2 \\
\hline Baccalaureate degree in nursing +PHD & 27 & 29.6 \\
\hline \multicolumn{3}{|l|}{ Academic rank: } \\
\hline Assistant professor & 5 & 5.4 \\
\hline Lecturer & 22 & 24.2 \\
\hline Assistant lecturer & 22 & 24.2 \\
\hline Demonstrator & 42 & 46.2 \\
\hline \multicolumn{3}{|l|}{ Department: } \\
\hline Psychiatric\& mental health nursing & 12 & 13.2 \\
\hline Community health nursing & 15 & 16.5 \\
\hline Maternal \&newborn health nursing & 15 & 16.5 \\
\hline Medical-surgical nursing & 21 & 23 \\
\hline Pediatric nursing & 13 & 14.3 \\
\hline Nursing administration & 15 & 16.5 \\
\hline \multicolumn{3}{|l|}{ Experience in teaching nursing( years): } \\
\hline$<5$ & 22 & 24.2 \\
\hline $5-$ & 34 & 37.3 \\
\hline $10+$ & 35 & 38.5 \\
\hline Marital status; Single & 32 & 35.2 \\
\hline $\begin{array}{l}\text { Monthly income (L.E.): } \\
<1500\end{array}$ & 32 & 35.2 \\
\hline
\end{tabular}

Table 2. Components and overall level of emotional intelligence of participants (No $=91)$

\begin{tabular}{|c|c|c|c|c|}
\hline \multirow{2}{*}{ Components of emotional intelligence } & \multicolumn{2}{|c|}{ Low $(<75 \%)$} & \multicolumn{2}{|c|}{ High $(75 \%+)$} \\
\hline & No & $\%$ & No & $\%$ \\
\hline Social skills & 78 & 85.7 & 13 & 14.3 \\
\hline Optimism & 48 & 52.7 & 43 & 47.3 \\
\hline Regulations of emotions in self and others & 80 & 87.9 & 11 & 12.1 \\
\hline Utilization of emotions in solving problems & 76 & 83.5 & 15 & 16.5 \\
\hline Expression of own \&others emotions & 76 & 83.5 & 15 & 16.5 \\
\hline Total emotional intelligence & 72 & 79.1 & 19 & 20.9 \\
\hline
\end{tabular}

Table 3 indicates that the majority $84.6 \%(n=77)$ of the faculty members reported experiencing high levels of occupational stress, while $15.4 \%(\mathrm{n}=14)$ were experiencing a low occupational stress. The same table also shows that career development had the highest percent (93.4\%), and ranked first as the greatest source of stress to faculty members, followed by stress from work overload (89\%) and inadequate resources $(80.2 \%)$. However, stress related to lack of reward 
ranked last $(69.2 \%)$. The same table reveals that the majority $85.7 \%(\mathrm{n}=78)$ of the participants had low level of selfefficacy while, $14.3 \%(n=13)$ had high level of self-efficacy.

Table 3. Level and percentages of occupational stress domains and perceived self-efficacy of participants (no $=91$ )

\begin{tabular}{|c|c|c|c|c|}
\hline \multirow{2}{*}{ Occupational stress domains \& self-efficacy } & \multicolumn{2}{|c|}{ Low $(<75 \%)$} & \multicolumn{2}{|c|}{ High $(75 \%+)$} \\
\hline & No & $\%$ & No & $\%$ \\
\hline \multicolumn{5}{|l|}{ Domains of occupational stress: } \\
\hline Work overload & 10 & 11.0 & 81 & 89 \\
\hline Poor management practice & 21 & 23.1 & 70 & 76.9 \\
\hline Interpersonal relationship & 25 & 27.5 & 66 & 72.5 \\
\hline Career development & 6 & 6.6 & 85 & 93.4 \\
\hline Work scheduling & 20 & 22 & 71 & 78 \\
\hline Inadequate resources & 18 & 19.8 & 73 & 80.2 \\
\hline Lack of reward & 26 & 30.8 & 63 & 69.2 \\
\hline Job insecurity & 19 & 20.9 & 72 & 79.1 \\
\hline Poor working condition & 20 & 22 & 71 & 78 \\
\hline Total occupational stress & 14 & 15.4 & 77 & 84.6 \\
\hline Total Self efficacy & 78 & $85.7 \%$ & 13 & 14.3 \\
\hline
\end{tabular}

We examined the correlations between the three study variables and personal characteristics of participants. Statistically significant positive correlations were detected between emotional intelligence, self-efficacy and personal characteristics of participants related to age and years of experience in teaching nursing $(r=428, .412, .240, \& 318 ; p=.000, .000, .022$, \& 002 respectively). However, there is negative correlation between occupational stress and personal characteristics of participants related to age, years of experience and monthly income $(r=-.498,-.434, \&-.232 ; p=.000, .000, \& .027$ respectively).

Table 4 shows the relation between the three study variables and academic rank of participants. There were statistically significant differences across the different academic ranks. Lecturers and Assistant professors had more emotional intelligence and sense of self efficacy than those in the other two categories (demonstrators and Assistant lecturers).

Table 4. The relation between emotional intelligence, self-efficacy, occupational stress scores and academic rank of participants

\begin{tabular}{|c|c|c|c|c|c|c|c|c|c|}
\hline \multirow{3}{*}{ Variable } & \multirow{3}{*}{ Score } & \multicolumn{6}{|c|}{ Academic rank } & \multirow{3}{*}{ Test } & \multirow{3}{*}{$p$} \\
\hline & & \multicolumn{2}{|c|}{$\begin{array}{l}\text { Demonstrator } \\
(\mathrm{no}=42)\end{array}$} & \multicolumn{2}{|c|}{$\begin{array}{l}\text { Assistant lecturer } \\
(\mathrm{no}=22)\end{array}$} & \multicolumn{2}{|c|}{$\begin{array}{l}\text { Lecturer \& } \\
\text { Assistant professor } \\
(\text { no }=27)\end{array}$} & & \\
\hline & & No & $\%$ & No & $\%$ & No & $\%$ & & \\
\hline \multirow{2}{*}{$\begin{array}{l}\text { Emotional } \\
\text { intelligence }\end{array}$} & High & 3 & 3.3 & 2 & 2.2 & 13 & 14.3 & \multirow{2}{*}{19.50} & \multirow{2}{*}{$<.001 * *$} \\
\hline & Low & 39 & 42.8 & 20 & 22 & 14 & 15.4 & & \\
\hline \multirow{2}{*}{ Self-efficacy } & High & 3 & 3.3 & 2 & 2.2 & 8 & 8.8 & \multirow{2}{*}{7.42} & \multirow{2}{*}{$<.05^{*}$} \\
\hline & Low & 39 & 42.8 & 20 & 22 & 19 & 20.9 & & \\
\hline \multirow{2}{*}{ Occupational stress } & High & 37 & 40.6 & 20 & 22 & 20 & 22 & \multirow{2}{*}{3.36} & \multirow{2}{*}{$>.05$} \\
\hline & Low & 5 & 5.5 & 2 & 2.2 & 7 & 7.7 & & \\
\hline
\end{tabular}

Correlations between faculty members' occupational stress, emotional intelligence, and self-efficacy scores are presented in Table 5. The table indicates a significant negative correlation between occupational stress and both of emotional intelligence and self-efficacy $(r=-.438$ and $-.291 ; p=<.001$ and .005 respectively). 
Table 5. Correlation between occupational stress, emotional intelligence, and self-efficacy scores

\begin{tabular}{lll}
\hline Variables & $\boldsymbol{p}$ & $\boldsymbol{r}$ \\
\hline Occupational stress with emotional intelligence & $<.001$ & $-.438^{* *}$ \\
Occupational stress with self-efficacy & $<.005$ & $-.291^{* *}$ \\
\hline
\end{tabular}

\section{Discussion}

This study investigates the relationship between occupational stress, emotional intelligence, and self-efficacy among faculty members in the Faculty of Nursing. The results from this study show that occupational stress was negatively related with self-efficacy and emotional intelligence. This could be attributed to the fact that the majority of participants are unaware of their emotions and could not regulate them in ways that can assist them in dealing with occupational stress. As well, they experience a low confidence in their capabilities which may have the tendency to look at things as if they are tougher than they really are, a belief that fosters stress, and a myopic vision of how best to tackle problems.

These findings go with the theoretical framework of the Cognitive Theory of Bandura, which states that there is a strong negative relationship between perceived self-efficacy and perceived stress ${ }^{[22]}$. The emotional intelligence model developed by Salovey and Mayer's which explains that the level of emotional intelligence will increase individuals' competencies and this can increase their ability to decrease stress situations ${ }^{[29]}$. These findings go in line with scattered previous studies $[1,15,26,27,36]$. These study findings are incongruent with what has been reported in other previous studies ${ }^{[32,37,38]}$ which found that emotional intelligence is significantly positively correlated with occupational stress among faculty members and school teachers.

The findings of the current study demonstrate that the majority of faculty members experience a high level of occupational stress. This may be due to the increased pressure arising from absence of relaxation as a result of intensive workload, attainment of career aspiration of academics, lack of resources, and poor working condition. These results are in congruence with a number of previous studies ${ }^{[6,21,39]}$. Our findings are against what has been reported in earlier studies ${ }^{[40,41]}$ indicating that the overall stress level of the university teachers was moderate.

The results of the present study reveal that career development, work overload, and inadequate resources were found to be the most stressful factors experienced by faculty members. This result could be due to the greater responsibilities of nurse educators emanating from teaching responsibilities and their duties toward the quality control and accreditation making them worked longer hours than they chose to or want to and often during weekends, as well as, the lack of supplies and equipment that will help them accomplish these tasks, in addition to the pressure from attainment of career aspiration of academics. Career development expressed by rise in rank and consequently increased salaries and benefits hinges on faculty member's research productivity. Hence, research attracts the highest consideration for promotion. These findings are in accordance with a number of previous studies ${ }^{[42-44]}$.

In spite of lack of reward was found to be the least stressful factor experienced by faculty members this may be due to the recent increase in their salaries but this percent is still high because this increase is still not covering their economic demands of life and research costs. These results are consistent with the data reported by Mohammed ${ }^{[44]}$.

The researchers dealt with the emotional intelligence variables as dichotomous variables to be able to compare their results with previous studies that examine emotional intelligence. The findings of the current study reveal that the majority of faculty members experience a low level of emotional intelligence. This may be attributed to the deficient curriculum in this area, which does not adopt emotional intelligence skills as a goal for educational reform, for them, throughout the years of academic study. As well as the absence of any training courses/ programs on emotional intelligence for faculty members, these findings are in accordance with those of Mohammed ${ }^{[31]}$. The present study findings however were in disagreement with what has been reported in other previous studies ${ }^{[45,46]}$ which show that the majority of teachers have a moderate level 
of emotional intelligence, and, that of a very recent study ${ }^{[47]}$ which found that the emotional intelligence of teachers reached was high.

Regarding to components of emotional intelligence, about half of the participants reported that the optimism was the highest component of emotional intelligence. This may be due to some extent of them have the ability to maintain a positive attitude even in the face of adversity but this percent is still low. On the other hand, the lowest component was related to regulations of emotions in self and others, this may be attributed to the lack of participants' knowledge and skills about emotional intelligence leading to inadequate capabilities to regulate their emotions and others' emotions in controlling psychological stress. This finding is inconsistent with the result of Mohammed ${ }^{[31]}$ who found the highest component of emotional intelligence was understanding of emotions while the lowest was related to management of emotions.

The findings of the current study demonstrate that the majority of participants had a low sense of self efficacy. This may be due to many factors such as; poor condition in the faculty environment, inadequate resources that hinder them to find better instructional strategies to improve their teaching performance over time, lack of constructive feedback in which a faculty members receive verbal comments about their capabilities to master given tasks, in addition to exposure to job stress as a result of the burden of teaching tasks without adequate reward, these factors lead to lower their level of efficacy. The present study findings are contradicting with what has been reported in a Turkish study ${ }^{[48]}$ which found that the school teachers have higher self-efficacy beliefs.

The results of the present study imply that there are negative correlations between occupational stress and personal characteristics of the sample with particular reference to age, years of experience in teaching nursing, and monthly income. However, the correlation is not significant with the academic rank. The major explanation for such a finding is that, older faculty members with more experience in teaching are more experienced and adaptable to the environment that helping to use active coping strategies and had a less job stress than younger staff.

The inadequate monthly income of the participants might make them difficult to meet the cost of living and other commitments costs especially for conducting scientific research that are causes of stress among them. Again, a faculty members in spite of their academic rank they are exposed to the same job pressure and the small sample size probably is exploring why there is no statistically significant differences in the occupational stress scores of the participants based on academic rank. These findings are in line with those of a research conducted by Khurshid et al. ${ }^{[6]}$. However, these study findings were against what has been reported in other previous studies for instance that of Fako ${ }^{[14]}$ which demonstrated that there was no correlation between occupational stress and personal characteristics of faculty members. Similarly, other studies ${ }^{[43,44]}$ found a positive relationship between occupational stress and personal characteristics of faculty members.

The findings of the current study demonstrate that there are significant positive correlations between emotional intelligence, self-efficacy, and personal characteristics of faculty members with reference to age, years of experience in teaching nursing and academic rank. This may be due to the faculty members who attained a higher level of qualification (teaching staff), the greater the age and length of teaching experience the higher the amount of maturation which ultimately leads to posses emotional and social competences and tend to find better instructional strategies to improve their teaching performance over time, thus increasing their sense of efficacy ${ }^{[49]}$. These findings go in line with a number of previous studies ${ }^{[50,51]}$. These study findings are against what has been reported in other previous studies ${ }^{[52]}$, which found that the teachers' perceived levels of efficacy in education do not change significantly by years of teaching experience. As well, Mohammed ${ }^{[31]}$ in her study demonstrated that no correlations were detected between emotional intelligence and personal characteristics of teachers in terms of age, years of experience, and job position.

\section{Limitation of the study}

This research has certain limitations due to which its results cannot be generalized. 
1) If the sample size would be larger, the generalization of results would be better.

2) The study was conducted at one setting.

3) The issue requires further investigations such as longitudinal studies are needed to evaluate the possibility of a causal relationship between occupational stress, emotional intelligence, and self-efficacy.

\section{Conclusion and recommendations}

The findings of current study confirm that occupational stress has negative relationships with the faculty members' emotional intelligence and self-efficacy. Based on the findings of this study, its recommended that:

- The Faculty of Nursing should keep the stress level of their faculty members lower and help them to stay healthier by holding training courses on emotional intelligence improving their social skills (such as ability to leading change, persuasiveness, verbal listening skill, and leading teams), and increase their efficiency at work.

- The university management should provide a more supportive work environment to faculty members so they can perform their jobs more effectively, as well make more funds available to them for research and career development purposes.

- The head of the department always take into consideration equal distribution of duties among the faculty members to decrease the workload.

- The perceived self-efficacy can be improved among the faculty members through training programmes and courses designed with the sources such as mastery learning, vicarious experiences, specific positive feedback and psychological skills' training. This would help the faculty members enhance their stress bearing capacity and also improve their productivity.

- Further studies should investigate the relationship between these three studied variables occupational stress, emotional intelligence and self-efficacy, and the performance of nurse educators.

\section{References}

[1] Vaezi S, Fallah N. The Relationship between Self-efficacy and Stress among Iranian EFL Teachers. Journal of Language Teaching and Research [Internet]. 2011 Sep; 2(5): 1168-1174. Available from: ojs.academypublisher.com/index.php/jltr/article/download/

[2] Jennett H K, Harris S L, Mesibov G B. Commitment to philosophy, teacher efficacy, and burnout among teachers of children with autism. Journal of Autism and Developmental Disorders. 2003 Dec; 33(6): 583-593. PMid:14714928 http://dx.doi.org/10.1023/B:JADD.0000005996.19417.57

[3] Bandura A. Self-efficacy in changing societies. NewYork: Cambridge University Press; 1995. 178. http://dx.doi.org/10.1017/CBO9780511527692

[4] Ruble LA, Usher E L, McGrew J H. Preliminary Investigation of the Sources of Self-Efficacy among Teachers of Students with Autism. Focus on Autism and Other Developmental Disabilities journal [Internet].2011 Jun; 26(2): 67-74.

Available from: http://www.ncbi.nlm.nih.gov/pubmed/

[5] Kaut D S, Kaur R. Study of Emotional Intelligence and Teacher Stress among B.Ed Teachers. International Journal of Research in Education Methodology [Internet]. 2013; 3(2): 248-254. Available from: http://cirworld.com/index.php/IJREM/article/view/1828/pdf_10

[6] Khurshid F, Butt Z U, Malik S K. Occupational Role Stress Of The Public and Private Sector Universities Teachers. Language India Journal [Internet]. 2011; 11(8): 354, 353-366. Available from: http://www.languageinindia.com

[7] Rosenthal T, Alter A. Occupational stress and hypertension. Journal of the American society of hypertension [Internet]. 2012 Jan; 6(1): 2-22. Available from: http://www.ashjournal.com/article PMid:22024667 http://dx.doi.org/10.1016/j.jash.2011.09.002

[8] Kauts A, Saroj R. Study of Teacher Effectiveness and Occupational Stress In Relation to Emotional Intelligence among Teachers at Secondary Stage. Journal of history and social sciences [Internet]. 2010 Dec; 1(1):12-22. Available from:

http://jhss.org/archivearticleview 
[9] Nakao M. Work related stress and psychosomatic medicine. BioPsychoSocial Medicine Journal [Internet]. 2010; 4(1): 1-8. Available from: http://www.bpsmedicine.com/content

[10] Eres F, Atanasoska T. Occupational Stress of Teachers: A Comparative Study Between Turkey and Macedonia. International Journal of Humanities and Social Science [Internet]. 2011 Jun; 1(7): 59-65. Available from: http://www.ijhssnet.com

[11] Safaria T, Othman T. The Role of Leadership Practices on Job Stress among Malay Academic Staff: A Structural Equation Modeling Analysis. International Education Studies [Internet]. 2011 Feb; 4(1): 90-100. Available from: http://www.ccsenet.org/journal/

[12] Ahmdy S, Changiz T, Masiello I, Brommels M. Organizational role stress among medical school faculty in Iran: Dealing with role conflict. Medical Education Journal [Internet]. 2007 May; 7(14):1-10. Available from: http://www.biomedcentral.com/content/pdf/

[13] Oginska-Bulik N. Occupational stress and its consequences in healthcare professionals: the role of type D personality. International Journal of Occupational Medicine and Environmental Health. 2006; 19(2): 113-122. PMid:17128809 http://dx.doi.org/10.2478/v10001-006-0016-7

[14] Fako TT. Occupational Stress among University Employees in Botswana. European Journal of Social Sciences [Internet]. 2010 Aug; 15(3): 313-326. Available from: http://connection.ebscohost.com/c/articles/

[15] Salami S O. Occupational stress and well-being: emotional intelligence, self-efficacy, coping, negative affectivity and social support as moderators. The journal of international social research [Internet]. 2010 Aug; 3(12):387-398. Available from: http://www.sosyalarastirmalar.com/cilt3/sayi12pdf.

[16] Indoo S, Ajeya J. Emotional Intelligence and Occupational Stress among the Faculty Members of Private Medical and Engineering Colleges of Uttar Pradesh: A Comparative Study. Advances In Management [Internet]. 2012 July; 5(7): 52-57. Available from: http://www.shankargargh.net/management_back_issue/manage.

[17] Jhaa A, Singh I. Teacher Effectiveness in Relation to Emotional Intelligence Among Medical and Engineering Faculty Members. Europe's Journal of Psychology [Internet]. 2012 November; 8(4): 667-685. Available from: http://ejop.psychopen.eu/article/view

[18] Bar-On R. The impact of emotional intelligence on subjective well-being. Perspectives in Education. 2005; $23(2): 41-61$.

[19] Kaut D S, Kaur R. Study of Emotional Intelligence and Teacher Stress among B. Ed Teachers. International Journal of Research in Education Methodology. 2013; 3(2): 248-254.

[20] Burger T. Emotional intelligence and well- being in teachers [dissertation]. [South African]: University of Stellenbosch; 2009.110.

[21] Yong W. Research on the source of occupational stress of college teachers. Proceedings of the international conference on human health \& biomedical engineering; 2011 Aug19-22; Jilin, China: Institute of Electrical and Electronics Engineers, [Internet]; 2013.674.

[22] Bandura A. Self-efficacy: The exercise of control. New York: W. H. Freeman; 1997: 2-8.

[23] Skaalvik E M, Skaalvik S. Dimensions of teacher self-efficacy and relations with strain factors, perceived collective teacher efficacy, and teacher burnout. Journal of Educational Psychology [Internet]. 2007 Aug; 99(3): 611-625. Available from: http://psycnet.apa.org/index.cfm http://dx.doi.org/10.1037/0022-0663.99.3.611

[24] Wolters C A, Daugherty S G. Goal structures and teachers' sense of efficacy: Their relation and association to teaching experience and academic level. Journal of Educational Psychology. 2007 Feb; 99(1): 181-193. http://dx.doi.org/10.1037/0022-0663.99.1.181

[25] Schwarzer R, Hallum S. Perceived Teacher self- Efficacy As a Predictor of Job Stress and Burnout: Mediation Analyses. Applied Psychology An International Review. 2008 Jan; 57(1): 152-171. http://dx.doi.org/10.1111/j.1464-0597.2008.00359.x

[26] Darvish H, Nasrollahi A A. Studying the Relations between Emotional Intelligence and Occupational Stress: A Case Study at Payame Noor University. Journal of Economic Sciences Series. 2011; LXIII (2): 38-49.

[27] Adeyemo D A, Ogunyemi B. Emotional intelligence \& Self- Efficacy as Predictors of Occupational Stress Among Academic staff in a Nigerian University. E-Journal of organizational learning and leadership. 2005; 7(2): 1-14.

[28] Salovey P, Mayer J. EI, imagination, cognition \& personality. New York: Bay wood publishing Inc; 1990. $185-211$.

[29] Salovey P, Mayer J. EI meets traditional standards for an intelligence. New York: Bay wood publishing Inc; 1997. $27,267-298$.

[30] Schutte N S, Malouff J M, Hall LE, Haggerty D J, Cooper JT, Golden C J, Dornheim L. Development and Validation of a Measure of Emotional Intelligence. Personality and Individual Differences.1998; 25(2): 167-177. http://dx.doi.org/10.1016/S0191-8869(98)00001-4

[31] Mohammed F H. Exploring the relationship between emotional intelligence and leadership styles among head nurses at zagazig university hospitals [dissertation].[Egypt]: Zagazig university; 2011.51,72,77.

[32] Jude A M. Emotional Intelligence, Gender and Occupational stress among secondary school teachers in Ondo State, Nigeria. Pakistan Journal of Social Sciences. 2011; 8(4):159-165.

[33] Akpochafo G O. Emotional Intelligence and Self Efficacy as Correlates of Career Commitment in Nigeria. An International Multi-Disciplinary Journal. 2011 Jan; 5(1): 212-225. 
[34] Schwarzer R, Jerusalem M. Generalized Self-Efficacy scale. In Weinman J, Wright S, Johnston M(Eds.). Measures in health psychology: A user's portfolio. Causal and control beliefs. UK: Nfer-Nelson, Windsor. 1995; 35-37.

[35] Hassan T, Hassan M. Development and Validation of Occupational Stress Scale. Unpublished monograph, Department of Educational Foundation and Management, Olabisi Onabanjo University, Ago-Iwoye, Nigeria.1998.

[36] Verešová M, Malá D. Stress, Proactive Coping and Self- Efficacy of Teachers. Procedia - Social and Behavioral Sciences. 2012 Oct; 55: 294-300.

[37] Brackett M A, Palomera R, Mojsa-Kaja J, Reyes M R, Salovey P. Emotion regulation ability, burnout, and job satisfaction among British secondary school teachers. Psychology in the schools. 2010 April; 47(4): 406-417.

[38] Nooryan K H, Gasparyan K H, Sharif F, Zoladl M. The Effect of Teaching Emotional Intelligence (EI) Items on Job Related Stress in Physicians and Nurses Working in ICU Wards in Hospitals, Yerevan, Armenia. International Journal of Collaborative Research on Internal Medicine \& Public Health. 2011 Oct; 3(10): 704-713.

[39] Michailidis M P. Gender-related work stressors in tertiary education. Journal of Human Behavior in the Social Environment.2008 Oct; 17(2):195-211. http://dx.doi.org/10.1080/10911350802171203

[40] Reddy G L, Poornima R. Occupational Stress and Professional Burnout of University Teachers in South India. International Journal of Educational Planning \& Administration. 2012; 2(2): 109-124.

[41] Pabla M S, Occupational Stress Amongst Teachers of Professional Colleges in Punjab. Indian Journal of Research. 2012 Sep; 1(9): 112-113.

[42] Aniedi A I, Offiong B A, Out E D. Occupational Stress Sources among University Academic Staff. European Journal of Educational Studies. 2010 Oct; 2(3): 217-225.

[43] Akbar A, Akhter W. Faculty stress at higher education: a study on the business schools of Pakistan. Journal of World academy of science, engineering and technology. 2011 Jun; 49: 1079-1083.

[44] Mohammed H M. Job stressors and burnout among faculty members and assistants in faculty of nursing at Zagazig University [dissertation]. [Egypt]: Zagazig University; 2012. 101.

[45] Edannur S. Emotional Intelligence of Teacher Educators. International Journal of Education Science. 2010 Dec; 2(2): $115-121$.

[46] Nasir Z A, Mustaffa M S, Ahmad R. The Relationship Between Emotional Intelligence With Skills Competency And Personal Development Among Counseling Teachers In Kulaijaya District, Johor. International journal of fundamental psychology \&social science. 2011 Sep; 1(1): 17-20.

[47] Thilagavathy T. Adjustment and emotional intelligence of high school teachers in Tiruvarur district. International Journal of Teacher Educational research. 2013 May; 2(5): 1-6.

[48] Senemoglu N, Demirel M, Yagci E, Ustundag T. Elementary school teachers, self-efficacy beliefs: A Turkish case. Humanity and social sciences journal. 2009; 4(2): 164-171.

[49] Yenice N. Search of Science teachers, teacher efficacy\& self-efficacy levels relating to science teaching for some variables. Procedia social and behavioral sciences. 2009; 1: 1062-1067. http://dx.doi.org/10.1016/j.sbspro.2009.01.191

[50] Obradovic V, Jovanovic P, Petrovic D, Mihic M, Mitrovic Z. Project Managers' Emotional Intelligence - A Ticket to Success. Procedia - Social and Behavioral Sciences. 2013 Mar; 74: 274-284.

[51] Klassen R M, Chiu M M. Effects on teachers' self-efficacy and job satisfaction: Teacher gender, years of experience, and job stress. Journal of Educational Psychology. 2010 Aug; 102(3): 741-756. http://dx.doi.org/10.1037/a0019237

[52] Anai N N. Teachers emotional intelligence, job satisfaction, and organizational commitment. Journal of Workplace Learning. 2012; 24(4): 256-269. http://dx.doi.org/10.1108/13665621211223379 